\title{
Prader-Willi syndrome and psychotic symptoms: report of a further case
}

\begin{abstract}
*David J Clarke, MRC Psych, Senior Lecturer in Developmental Psychiatry, Centre for Research and Information in Mental Disability, Department of Psychiatry, University of Birmingham, Queen Elizabeth Psychiatric Hospital, Edgbaston, Birmingham, B15 2QZ, England. Tessa Webb, BSc PhD, Clinical Genetics Unit, Department of Paediatrics and Child Health, University of Birmingham, Maternity Hospital, Birmingham, B15 2TG, England. Joyce P Bachmann-Clarke, MA PhD, University of Basel, Basel, Switzerland.

*Correspondence
\end{abstract}

\begin{abstract}
A 21 year-old woman with Prader-Willi syndrome (PWS) and a delusional disorder (paranoid psychosis) is described. Other reports of psychoses associated with PWS are reviewed. Reasons for the co-existence of the two disorders are considered, with discussion of the possible role of auditory information processing deficits in the genesis of psychotic symptoms. Such symptoms must be differentiated from maladaptive behaviours not arising from psychosis, the latter being relatively common in PWS. Treatment with a small dose of flupenthixol greatly reduced the impact of the patient's psychotic symptoms, with a corresponding improvement in her quality of life.
\end{abstract}

Key words: Prader-Willi syndrome; Psychiatry; Psychoses; Genetics: behavioural aspects; Mental retardation.

\section{Introduction}

Prader-Willi syndrome is a developmental disorder characterised by neonatal hypotonia and feeding difficulty, followed by a switch to marked over-eating which occurs during early childhood. Affected adults are of short stature, have a characteristic facial appearance and small hands and feet, and hypogonadism. Most are obese, but dietary management from childhood may avoid the extreme obesity which has previously been characteristic of the condition. Cognitive impairment is usual, but not all affected people have cognitive and social impairments which are so severe as to constitute mental retardation..$^{1.2}$ The majority of people with the disorder (about $60 \%$ ) have a paternally-derived deletion of the long arm of chromosome 15 at q11-q13. Other abnormalities which may occur include maternal disomy (the inheritance of two number 15 chromosomes from the mother), translocations (with associated deletions) and rearrangements of material on $15 \mathrm{q}$. PWS is thought to result from the lack of a paternally derived contribution to the relevant area of chromosome 15, and genomic imprinting has been suggested as a mechanism through which uniparental disomy could result in the disorder. ${ }^{3,4}$

PWS is associated with a variety of maladaptive behaviours in addition to extreme hyperphagia. These include temper tantrums, self-injury through picking at skin, resistance to change, sleep problems, and oppositional/defiant or 'stubborn' behaviour. ${ }^{5-10}$ Some of these maladaptive behaviours have been considered so characteristic of PWS that they have been incorporated into diagnostic criteria."

In the course of research into behavioural aspects of PWS, three people with PWS and psychoses were described. ${ }^{12} \mathrm{~A}$ further case has now been assessed, and is reported here.

\section{Case report}

$\mathrm{E}$ was born in 1972. She has a twin brother and an older sister. She had the extreme neonatal hypotonia and feeding difficulty which are characteristic of PWS, although the diagnosis was not made until she was 19 years old. She developed hyperphagia during childhood and consequently gained weight. There is no family history of learning disability or of psychiatric illness.

At the age of $20 \mathrm{E}$ moved to her current residential placement, a rehabilitation facility which aims to improve the daily living skills and communicatory ability of people with learning disabilities. Although $\mathrm{E}$ had, like many people with PWS, been prone to outbursts of temper in response to apparently minor frustrations or changes in routine, she made good progress after the move, which was planned and apparently welcomed by $E$. Because her outbursts of temper seemed more frequent premenstrually, she had been prescribed noresthisterone from the age of 20.

After six months residence at the rehabilitation facility, $\mathrm{E}$ became increasingly suspicious and started to seek reassurance that members of staff were not telephoning her parents to complain about her. Initially she was able to accept some reassurance that staff were not behaving in this way, but over the following six months she became increasingly resistant to reason or explanation, and eventually became convinced that staff were discussing her in a critical manner between themselves and in telephone conversations with her parents. A referral for a psychiatric opinion was made following advice from the Prader-Willi Syndrome Association (UK).

When assessed, E was $1.47 \mathrm{~m}$ tall and weighed $66.4 \mathrm{~kg}$ (body mass index 30.74). She had fair hair and blue/grey eyes, and the dysmorphology typical of Prader-Willi syndrome. She also had small hands and feet (palm length $9.5 \mathrm{~cm}$, mid finger length $6.1 \mathrm{~cm}$, foot length $19.2 \mathrm{~cm}$ ) and a cognitive impairment. $E$ also had an articulation disorder, and communicated with a mixture of speech and makaton sign language. She had no hearing impairment. She was able to describe her problems and said that she was sure staff at the unit were making derogatory comments about her. She was especially concerned that the staff were talking to her parents by telephone, which she believed was happening several times each day. For this reason she was reluctant to leave groups of people, (eg. to go to bed in the evening). She also said that on one occasion she had heard her father talking about her when 
she was talking to her mother on the telephone, at a time when her father was not present in the room with her mother. She may have experienced auditory hallucinations on other occasions but it was not possible to be certain about this, and auditory hallucinations did not seem to be a prominent feature of the disorder. $E$ was unable to say why people should wish to discuss her with her parents but felt sure that this was happening, and that the comments were adverse.

The staff reported that if E could hear clearly what people were saying to each other, there were rarely problems. If she could hear staff talking in an adjacent room, or when ambient noise made it difficult for her to distinguish what was being said, she would become very distressed and shout. This was a marked change from her behaviour and demeanour when she first moved to the unit. The allegations that staff had 'phoned or had discussed her' would often be associated with an outburst of temper, so that the frequency of temper 'tantrums' had increased markedly over the months before the assessment.

$\mathrm{E}$ was not low in mood, and she had no consistent sleep disturbance or other features suggestive of an affective disorder. Her speech was rational, but poorly enunciated. She had no abnormal or inexplicable bodily sensations, and she did not describe or hint at passivity experiences. There had been no change in her memory or orientation, and her self-help skills were largely unchanged (there had been a slight deterioration because she often interrupted tasks to accuse a member of staff of talking about her).

The staff described a marked but gradual change in E's functioning as a result of her illness, and at the time of assessment her suspiciousness and abnormal beliefs were such that she was unable to engage in many of her usual activities. She had become more socially withdrawn than previously, but this was not a major problem. E was physically healthy and routine investigations, including thyroid function tests, did not show any abnormality.

The disorder fulfilled ICD-10 Diagnostic Criteria for Research for delusional disorder (F22.0) or a provisional diagnosis of organic delusional disorder (F06.2) depending on whether Prader-Willi syndrome is regarded as a "systemic physical disorder known to cause cerebral dysfunction". ${ }^{13}$ This is discussed below.

Treatment with oral flupenthixol (1mg daily for one week increasing to $2 \mathrm{mg}$ daily thereafter) was started. Over the following weeks $E$ became much less distressed by her abnormal ideas, and sought reassurance far less often. She was again able to engage in day-to-day activities and to resume some of her previous leisure interests. The episodes of loss of temper, which had been more frequent and more severe while $E$ had the abnormal ideas, returned to the pattern seen prior to the onset of the disorder.

Chromosome 15 studies showed a deletion of 15 (q11q13) which was detectable with molecular techniques, but not visible cytogenetically. E's fair skin and hair colouring compared to the rest of her family probably results from this deletion. ${ }^{14}$

At five month follow-up E remains much improved, with only occasional ideas that she is being talked about and with a marked improvement in her social functioning. Unfortunately, she has gained weight (current weight $71.4 \mathrm{~kg}$ ). It is possible that treatment with antipsychotic medication has contributed to the weight gain.

\section{Discussion}

In addition to the three cases reported previously, ${ }^{12}$ there is a description of a 20 year old man with PWS who had two psychotic episodes in which delusions and hallucinations were prominent, with a full recovery. The authors concluded that: "Viewing the disorder cross-sectionally, it fits best within the group of schizophrenic psychoses with the predominant characteristic feature of paranoia. The way the illness developed, with the acute symptoms disappearing completely on two occasions, makes one think that the patient has an endogenous agitated depressive, paranoidly coloured disorder of the cycloid type". ${ }^{15}$ Other descriptions of cases or series of people with PWS mention psychotic symptoms, including a description of two (out of 40) people with PWS who had "hallucinations and withdrawal and required admission"; ${ }^{16}$ a report of 12 out of 35 people with PWS who had "occasional auditory hallucinations";" and a report of a 36 year old woman with mosaicism for del 15 (q11.1 q11.2), hypothyroidism and hospital admissions because of "extreme restlessness, psychosis and disruptive behaviour which requires phenothiazine medication" which the authors felt was unrelated to her hypothyroidism. ${ }^{17}$ Jerome $^{18}$ described a 31 year old woman with PWS and a rapid cycling bipolar affective disorder which responded to treatment with fluoxetine and lithium, and suggested that a previously reported case ${ }^{19}$ may also have had a bipolar disorder associated with PWS. A case of Prader-Willi syndrome associated with cycloid psychosis was presented at the Third International Symposium of the Society for the Study of Behavioural Phenotypes. ${ }^{20}$

It is not possible to conclude that psychoses are more prevalent among people with PWS, or that there is a particular association between the two types of disorder, on the basis of isolated case reports. However, PWS is a relatively rare disorder, affecting about one in 15,000 people aged 0 to 25 years $^{21}$ and population-based studies would therefore be difficult to carry out. The most appropriate methodology would be to follow up children with PWS through adult life, and document abnormalities in behaviour and psychopathology as they occur. No such study has so far been carried out, to the authors' knowledge.

The association with psychotic symptoms may be due to chance, or to the effect of cognitive impairment (or other intervening or associated variables) rather than being specific to PWS. People with mental retardation have an increased prevalence of psychotic and other psychiatric disorders compared to the general population. ${ }^{22}$ The study of homogeneous groups of people with cognitive impairments (such as populations with PWS, fragile-X syndrome, Down syndrome, etc) is likely to shed light on the factors underlying this increased risk. It has been noted that people with PWS have relative deficits in auditory/verbal information processing, and relative strengths in visual perception and visual/motor task performance, ${ }^{23}$ and this may be relevant to the pathogenesis of psychotic symptoms. A predisposition to symptoms such as ideas of reference, delusions and possibly auditory hallucinations may arise through auditory misperception or dysfunctional auditory information processing. Such deficits may also partly explain the 'stubbornness' or lack of amenability to reason (presented aurally) which has been described in association with PWS.

This patient's disorder is probably best viewed as an organic delusional disorder, although ICD-10 Research 
Diagnostic Criteria only allow a provisional diagnosis to be made where it cannot be demonstrated that "there is recovery from or significant improvement in the mental disorder following removal or improvement of the underlying presumed cause". ${ }^{13}$ The most appropriate classification of psychotic symptoms occurring in association with PWS will only be possible when more is known about their pathogenesis, and about the cerebral dysfunction occurring in PWS. This may in turn be facilitated by further research into the pattern of cognitive abilities and impairments seen in PWS, and the nature and extent of other mental and behavioural abnormalities associated with the condition.

The woman reported here was referred specifically because one author (DC) has a special interest in psychoses and behaviour disorders associated with developmental disorders. The population of people with PWS with whom he is in contact is likely to be biased towards those with more behavioural and psychiatric morbidity.

The authors therefore urge some caution when interpreting this observation of a further case of psychotic symptoms associated with PWS. However, we hope that it may stimulate other reports of the association, if this is more common than previously recognised, and research into the pathogenesis of such symptoms.

The improvement in quality of life following treatment was remarkable for this patient. It is important that psychotic symptoms are recognised and treated when they do occur in association with developmental disorders, and that they are differentiated from maladaptive or non-specific 'challenging' behaviours arising for other reasons, and with other implications for treatment. Prader-Willi syndrome is said by some carers to be associated with unusual sensitivity to the effects of some psychoactive medications, but there has been little research in this area. One study noted that six out of 42 adults with PWS given psychoactive medication had medication withdrawn "due either to toxicity or ineffectiveness", ${ }^{24}$ and another urged caution in the use of antipsychotics to treat non-psychotic behavioural abnormalities associated with PWS. ${ }^{19}$ Low doses of psychotropic medications would therefore seem advisable when initiating treatment.

\section{References}

1. Prader A, Labhart A, Willi H. Ein Syndrom von Adipositas, Kleinwuchs, Kryptorchismus und Oligophrenie nach myatonieartigem Zustand im
Neugeborenalter. Schweiz Med Wochenschr 1956; 86: 1260-1.

2. Butler MG. Prader-Willi syndrome: current understanding of cause and diagnosis. Am J Med Gen 1990; 35: 319-32.

3. Knoll JHN, Wagstaff J, Lalande M. Cytogenetic and molecular studies in the Prader-Willi and Angelman syndromes. Am J Med Gen 1993; 46: 2-6.

4. Nicholls RD. Genomic imprinting and uniparental disomy in Angelman and Prader-Willi syndromes: a review. Am J Med Gen 1993; 46: 16-35.

5. Dunn HG. The Prader-Labhart-Willi syndrome: review of the literature and report of nine cases. Acta Paed Scand 1968; Suppl 186: 1-38.

6. Greenswag LR. Adults with Prader-Willi syndrome: a survey of 232 cases. Dev Med Child Neurol 1987; 29: 145-52.

7. Whitman BY, Accardo P. Emotional symptoms in Prader-Willi syndrome adolescents. Am J Med Gen 1987; 28: 897-905.

8. Clarke DJ, Waters J, Corbett JA. Adults with Prader-Willi syndrome: abnormalities of sleep and behaviour. J Roy Soc Med 1989; 82: 21-4.

9. Borghgraef M, Fryns JP, Van den Berghe H. Psychological profile and behavioural characteristics in 12 patients with Prader-Willi syndrome. Gen Counseling 1990; 1: 141-50.

10. Curfs LMG, Verhulst FC, Fryns JP. Behavioural and emotional problems in youngsters with Prader-Willi syndrome. Gen Counseling 1991; 2: 33-41.

11. Holm VA, Cassidy SB, Butler MG, Hanchett JM, Greenberg F, Whitman BY, Greenswag LR. Diagnostic criteria for Prader-Willi syndrome. In: Cassidy SB, editor. Prader-Willi Syndrome and other chromosome $15 q$ deletion disorders. NATO ASI Series H: Cell Biology Vol 61. Berlin: Springer-Verlag, 1992; $105-17$. 12. Clarke DJ. Prader-Willi syndrome and psychoses. Br J Psychiatry 1993; 163 : 680-4.

13. World Health Organisation. The ICD-10 Classification of Mental and Behavioural Disorders: diagnostic criteria for research. Geneva: World Health Organisation, 1993.

14. Nicholls RD. Genomic imprinting and candidate genes in the Prader-Willi and Angelman syndromes. Curr Opin Genet Dev 1993; 3: 445-56.

15. Kollrack HW, Wolff D. Paranoid-halluzinatorische Psychose bei PrdaerLabhart-Willi-Fanconi syndrome. Acta Paedopsychiatrica 1966; 33: 309-14. 16. Bray GA, Dahms WT, Swerdloff RS, Fisher RH, Atkinson RL, Carrel RE. The Prader-Willi syndrome: a study of 40 patients and a review of the literature. Medicine 1982; 62: 59-80.

17. Bhate MS, Robertson PE, Davison EV, Brummitt JA. Prader-Willi syndrome with hypothyroidism. J Ment Def Res 1989; 33: 235-44.

18. Jerome, L. Prader-Willi syndrome and bipolar illness. J Am Acad Child Adolesc Psychiatry 1993; 32: 876-7.

19. Tu J-B, Hartridge C, Izawa J. Psychopharmacogenetic aspects of Prader-Willi syndrome. J Am Acad Child Adolesc Psychiatry 1992; 31: 1137-40.

20. Verhoeven WMA, Tuinier S. Pharmacological advances in mental retardation; towards a specific phenotypical approach? Paper presented at the Society for the Study of Behavioural Phenotypes Third International Symposium; November 1994, Congrescentrum Rolduc, Maastricht.

21. Akkefeldt A, Gillberg C, Larsson C. Prader-Willi syndrome in a Swedish rural county: epidemiological aspects. Dev Med Child Neurol 1991; 33: 715-21.

22. Corbett JA. Psychiatric morbidity and mental retardation. In: Snaith P, James FE, editors. Psychiatric illness and mental handicap. London: Gaskell, 1979.

23. Curfs LMG. Psychological profile and behavioral characteristics in the PraderWilli syndrome. In: Cassidy SB, editor. Prader-Willi syndrome and other chromosome 15q deletion disorders. NATO ASI Series H: Cell Biology Vol 61. Berlin: Springer-Verlag, 1992; 211-21.

24. Whitman BY, Greenswag LR. The use of psychotropic medications in persons with Prader-Willi syndrome. In: Cassidy SB, editor. Prader-Willi syndrome and other chromosome 15q deletion disorders. NATO ASI Series H: Cell Biology Vol 61. Berlin: Springer-Verlag, 1992; 223-31.

Original manuscript received September 9,1994 Final revision accepted February 2, 1995. 